\title{
Education 4.0: Robotics Projects to Encourage 21st Century Skills
}

\author{
Deivid Eive dos S. Silva, UFPR, dessilva@inf.ufpr.br \\ Aline de Oliveira Sousa, UFPR, ninimec@gmail.com \\ Marcela R. Oliveira, UFPR, marcelaoliveiraribeiro@gmail.com \\ Marialina Corrêa Sobrinho, UFOPA, linasobrinho@gmail.com \\ Eduardo Todt, UFPR, todt@ufpr.br \\ Natasha Malveira C. Valentim, UFPR, natasha@inf.ufpr.br
}

\begin{abstract}
Education 4.0 is defined as a student-centered learning model that prepares young for the challenges of the 21st Century, how to deal with emerging technological resources and processes. This case study aimed to encourage 21st Century skills and competencies seen as relevant to Education 4.0, such as teamwork, communication, autonomy, creativity, and innovation. In this study, we analyzed the feedbacks collected to identify which skills were encouraged in undergraduate and graduate students during one semester of the Mobile Robotics discipline, using Project-Based Learning (PBL). Students carried out projects and answered a self-assessment questionnaire about their skills. The qualitative analysis of the case study followed the procedures of the Grounded Theory method. The results indicated that learning based on robotics projects could encourage teamwork, communication, and organization skills.
\end{abstract}

Keywords: Education 4.0; Robotics Projects; 21st-Century Skills

Resumo. A Educação 4.0 é definida como um modelo de aprendizagem centrado no estudante que prepara os jovens para os desafios do Século XXI, como lidar com os recursos e processos tecnológicos disruptivos. Este estudo de caso teve o objetivo de incentivar habilidades e competências do Século XXI vistas como importantes no contexto da Educação 4.0, tais como trabalho em equipe, comunicação, autonomia, criatividade e inovação. Neste estudo, analisou-se os feedbacks coletados para identificar quais habilidades foram incentivadas nos estudantes de graduação e pósgraduação durante um semestre da disciplina Robótica Móvel, usando Aprendizagem Baseada em Projeto (PBL). Os estudantes realizaram projetos e responderam um questionário de autoavaliação sobre as habilidades. A análise qualitativa deste estudo de caso seguiu os procedimentos do método Grounded Theory. Os resultados indicaram que a aprendizagem baseada em projetos de robótica pode incentivar habilidades de trabalho em equipe, comunicação e organização.

Palavras-Chave: Educação 4.0; Projetos de Robótica; Habilidades do Século XXI

\section{Introduction}

Industry 4.0, also known as the fourth Industrial Revolution, gains impulse through the digital age. Thus, emerging technologies such as Digital Platforms, Cloud Computing, Artificial Intelligence, Robotics, among others, collaborate to foster the most diverse segments of the industry (Oliveira and Sommer, 2017). Industry 4.0 focuses on data management, work systems through technology, communication, and work efficiency improvements related to human resources (Winanti et al., 2018).

Many companies have suffered impacts on their traditional structure with the advancement of Industry 4.0. In this process, other sectors were affected, mainly in the education sector. Consequently, there was a need for educational training more aligned 
with the contemporary world, which would prepare young people for the challenges of the 21st Century (Puncreobutr, 2016). In this sense, education needs to prepared future professionals to operate in this new market concept. Thus, students need to be prepared for much more than repetitive activities. Graduates should have been trained to adapt and have a dynamic mindset in the market. Based on this, the teacher could use emerging technologies in the classroom to encourage skills e competencies of the $21 \mathrm{st}$ Century to prepare young for Industry 4.0.

Emerging technologies could encourage students' skills and competencies, such as problem-solving, creativity, innovation, critical thinking, resilience, flexibility, and mastery of technologies. Thus, it is believed that it will be possible to transform young into autonomous, creative, and participative subjects, and, consequently, into more capable professionals for Industry 4.0 (Coskun et al., 2016). Besides, that active methodologies, such as Project-Based Learning (PBL), can make it possible to work on the protagonism of the student.

In the literature, skill is defined as Know-How, while competence is known as Know to Apply. According to the European Center for the Development of Vocational Training, skill is the ability to perform tasks and solve problems. Simultaneously, competence is the ability to apply learning results in a defined context, such as education, work, personal or professional development (CEDEFOP, 2008).

This paper presents a case study that aimed to encourage 21 st Century skills and competencies in undergraduate students in Computer Science and postgraduate in Informatics. For this, robotics projects were carried out in the classroom, following Project-Based Learning (PBL). The case study results indicated that learning based on robotics projects: a) encouraged skills such as teamwork, communication, and organization, seen as relevant in the context of Education 4.0, b) allowed active learning, and c) worked the protagonism of the student.

This paper is organized into 7 sections. Section 2 defines the main concepts and terms of Education 4.0 and presents some works related to Educational Robotics. Section 3 describes the planning and execution of the case study. Section 4 presents the quantitative analysis. Section 5 describes the qualitative analysis. Section 6 contains discussions. Finally, conclusions and future work are presented in Section 7.

\section{Background}

The first mention for Education 4.0 was given in 2015 by Scheer (apud Ciolacu et al., 2017). The term Education 4.0 is still considered recent, as there is still little scientific literature on this topic (Ayub et al., 2018). In Education 4.0, teaching happens as follows: information needs to be accessible, and students should learn to find it instead of the teacher offering it to them in a rigid structure. Besides, students need to be encouraged to improve and develop their competencies and skills rather than learning a set of predefined data (Intelitek, 2018).

There are different classifications for skills and competencies in the literature. These can be Organizational (time management, leadership, and planning), Communicative (negotiation and communication), Behavioral (initiative, creativity, ethics, and coherence), Cognitive (problem-solving, critical thinking, agility to make decisions, interpretation, reflection, generalization, abstract thinking), and Socioemotional (interpersonal relationships, teamwork, interest management, environmental 
awareness, self-confidence, self-development, integrity, persuasion, self-control of emotions, empathy, flexibility, emotional stability, collaboration, patience, enthusiasm, resilience, and optimism) (Mourtzis, 2018) (Cotet et al., 2017) (Piñol et al., 2017).

In Education 4.0, the learning process is expected to be personalized. Students have the flexibility to be responsible for building their knowledge with the freedom to achieve their desired goals (Hartono et al., 2018). This new parameter redefines the education format, known as Education 4.0.

The use of robotics has been one of the most investigated topics in Education 4.0 (Messias et al., 2018). Experts encourage its use to prepare students with 21st Century skills and competencies (Eguchi, 2018). In this sense, we conducted a literature review to identify how robotics activities could encourage 21 st Century skills and competencies in students. Thus, this paper presents the possibility of working robotics through the PBL to experience the characteristics of Education 4.0 in Higher Education.

\subsection{Related Works}

Different researches about educational robotics can be found in the literature. However, we prioritized the works that sought to encourage 21 st Century skills and competencies in students, as these studies are characterized as initiatives of Education 4.0. Some of these initiatives are presented below:

- Case study about the skills developed through robotics activities, without involving the competition. Thirty-four high school students participated following the LEGO Education Maker process, answered a self-assessment questionnaire about their developed skills, and participated in a focus group. This study focused on skills such as creativity and innovation, problem-solving, collaboration, communication, and learning to learn (Messias et al., 2018).

- Case study about the development and test robotic dolls to support early childhood students. Different types of robotic doll designs were considered before using a glove doll. Fifty-two five-year-old children were observed to assess the robot's performance, from which quantitative and qualitative data were collected. The study indicated that robotic toys could improve learning, creativity, imagination, and interaction (Causo et al., 2015).

- Experimental Study about Robotics and STEM (Sciences, Technologies, Engineering, and Mathematics) methodology with ninety-one teen students. This study aimed to investigate how students perceive educational robotics as a tool to improve 21 st-century skills, such as creativity, collaboration, and computational thinking, and to stimulate their interest in STEM. During the semester, students worked with robotics and evaluated their experience with a questionnaire. The results illustrated that educational robotics activities could increase students' interest in coding, Computer Science, and Engineering (Negrini and Giang, 2019).

In this section, researches were presented under different perspectives about the use of Robotics to encourage 21 st-century skills and competencies. Therefore, we chose to work with PBL in the discipline of Mobile Robotics, being one of the active methodologies not followed or mentioned in the identified works. Through PBL, we seek to personalize learning to encourage 21 st Century skills and competencies in 
undergraduate and postgraduate students, having as parameter the characteristics of Education 4.0.

\subsection{PBL and Educational Robotics}

Project-Based Learning, also known as Pedagogy of Project, relates theory and practice in the classroom. Therefore, learning takes place through a sequence of activities that have meaning for the student. These activities are based on a constructionist learning perspective, where the student learns by doing (Roessingh and Chambers, 2011).

In this sense, the student appears as the main actor in the construction of knowledge. It is up to the teacher to mediate (listen, question, guide) and provide the necessary subsidies for this to happen. The teacher is the one who needs to challenge him and create moments so that he can make regulations and formalize knowledge (English and Kitsantas, 2013).

The PBL seeks the realization of new pedagogical practices, to learn beyond the classroom. In this way, the teacher's project needs to be attractive so that the student can transform knowledge into something applicable to life. The student should develop relevant skills for their school education, such as cooperation, autonomy, creativity, among others (Bell, 2010).

Educational robotics create a conducive space for learning, where students can come together to solve real-world problems from projects. For this case study, we realized the possibility of working on educational robotics in conjunction with the PBL. Thus, a case study was carried out to analyze how this combination could encourage 21 st Century skills and competencies.

\section{Case Study}

This case study was carried out with thirty-two undergraduate and graduate students enrolled in the Mobile Robotics discipline from the Federal University of Paraná. The students were organized into five teams (two teams of seven students and three teams of six). The teams had the option to choose one of the three projects: a) Very Small Size Soccer (VSSS): physical robots soccer category; b) 3D Simulation of Humanoid Robot Football: virtual robots soccer category; and c) Drone challenge: the creation of an application to make the drone fly over a straight line. As proposed by the professor, these projects were performed over a semester to contextualize the contents of the class (the students applied the knowledge acquired in class in their projects) and check the skills encouraged and useful for students to produce robotics projects. The students organized themselves by affinity and, subsequently, filled out a characterization questionnaire to distribute tasks according to the existing skills and competencies. The characterization questionnaire indicated that students were beginners in robotics, having some skills in programming and teamwork experiences.

\subsection{Case Study Planning}

The case study was organized into two parts to identify the contribution of Robotics in conjunction with the PBL for an Education 4.0: implementation and evaluation. In the first part, the professor organized the classes' dynamics, which served as evaluative items to compose the students' grades. The delivery of tasks was organized into three modules: (T1) Specification of project, (T2) Prototype, and (T3) Product. Posteriorly, we prepare the necessary artifacts for conducting the study as (a) Informed Consent Form (ICF): to present the research in question and verify the consent of the students 
concerning their participation in the study, (b) Characterization Questionnaire: to support participants in project organization and task delegation, (c) Worksheet: to guide and specify stages T1, T2 and T3; and (d) Self-Assessment Questionnaire to verify the competencies and skills encouraged.

In the second part, the professor defined the participants' evaluation process. The students were evaluated based on the productions of T1, T2, and T3 modules, which should reflect the knowledge acquired by the student in the theoretical classes. Lastly, the self-assessment questionnaire was used to verify the 21 st Century skills and competencies encouraged during the semester.

For quantitative analysis, we organized the self-assessment questionnaire in six 21 st Century skills, such as (1) creativity and innovation, (2) problem-solving, (3) communication, (4) teamwork, (5) learning to learn, and (6) organization. These skills were chosen because they represent the most studied skills in the related works identified in the literature (Messias et al., 2018). However, students could outline other types of skills in open questions. For the qualitative analysis of the data obtained in this case study, the Atlas.ti version 6 tool was used, following the Grounded Theory method (Strauss and Corbin, 2014), detailed in Section V.

\subsection{Case Study Execution}

Initially, we explained to students how the study would be conducted. The participants signed the ICF. The professor defined the delivery dates of the modules.

T1 / Specification: in this stage, the students chose the project by preference, and the teams were formed. In sequence, a project manager was chosen to apply the characterization questionnaire with the team. This questionnaire sought to identify the profiles and characteristics of the members of each team. Thus, the project manager defined and distributed the tasks among the members, according to the competencies and skills. Subsequently, the group established the project design containing the requirements gathering, description, use case diagrams, and other artifacts.

T2 / Prototype: in this stage, the teams presented the project's idea through an application in progress. In this way, the participants used the materials available on the course page. They participated in classes and workshops related to specific content for each project, taught by the professor. In the end, the teams also presented a report with the description and indication of these project's development stage.

T3 / Product: In this stage, the teams performed the tests and validation of the product. Finally, the students demonstrated the work produced. The Simulator teams decided to present a friendly match to each other to expose their work (Figure 1). After the demonstrations, each team delivered the final project documentation.

Finally, the participants answered the self-assessment questionnaire about their participation in the study. In this sense, it was possible to verify how competencies and skills contributed to students' learning, having the robotics and PBL as supporting methodology. The data were analyzed quantitatively and qualitatively.

\subsection{Example of one project created}

For the Humanoid Robot 3D Football Simulator project, students used the UT Austin Villa code as a base. The participants were able to develop their heuristics in the base code. Consequently, the teams could add new skills to robots' skill sets, such as scoring barriers, attack strategies, and goal-kick defense. Figure 1 shows the friendly match 
between teams A and B of the simulator to present the project developed in the Mobile Robotics class.

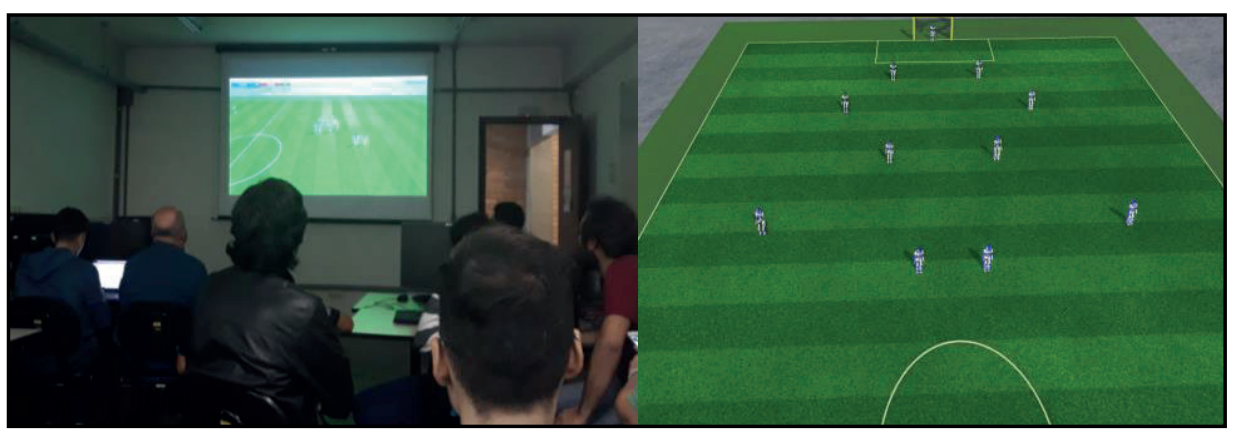

Figure 1 - Friendly match between teams A and B of 3D humanoid robot football simulator

\section{Quantitative Results}

At the end of this case study, of thirty-two participants, twenty students answered the self-assessment questionnaire. Figure 2 presents the results of the students' selfassessment on the skills encouraged in the projects. The sentences were organized using the following scale: (I) strongly disagree, (II) partially disagree, (III) neither agree nor disagree, (IV) partially agree, and (V) strongly agree. The scale is organized with the number of students concerning the skills encouraged.

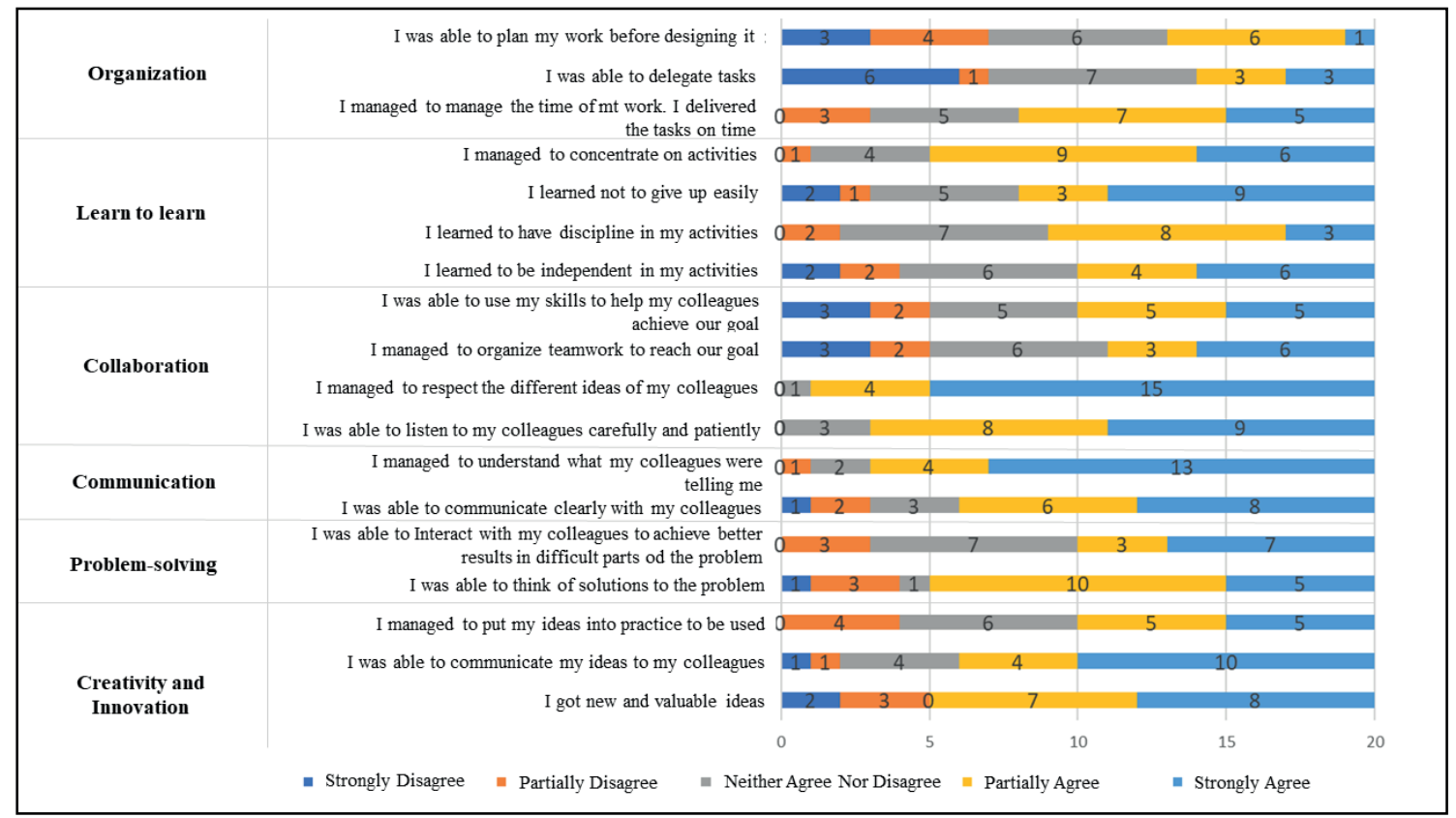

Figure 2 - Results of Students Self-Assessment Concerning Encouraged Skills

Through quantitative results, we identify that some students had a low development in organizational skills. In this sense, six students totally disagreed with the sentence "I was able to delegate tasks, I charged my colleagues to deliver parts of the work". Besides, seven students disagreed with the fact that they had planned the work before designing it. In sequence, we notice that some students were not prepared concerning the learning to learn skill. Seven students neither agreed nor disagreed with 
the sentence "I learned to have discipline in my activities". Moreover, six students neither agreed nor disagreed concerning learning to be independent in their tasks.

On the other hand, we note that students were optimistic about the skills of teamwork, communication, creativity, and innovation. Therefore, fifteen students totally agreed with the sentence "I was able to respect the different ideas of my colleagues". Besides, thirteen students totally agreed with the sentence "I was able to listen my colleagues carefully and patiently". Moreover, ten students totally agreed to "have been able to communicate their ideas to colleagues".

In addition to the closed questions, in the same self-assessment questionnaire, students still could report their experiences with robotics projects and how the $21 \mathrm{st}$ Century skills and competencies contributed to their learning. These reports have been analyzed qualitatively and are described in Section V.

\section{Qualitative Results}

The qualitative analysis was based on the Grounded Theory (GT) method (Strauss and Corbin, 2014). The qualitative data collected through the self-assessment questionnaire were analyzed using a subset of the steps in the coding process suggested by the GT method: open coding (1st step) and axial coding (2nd step).

After analyzing the qualitative data, codes were created (concepts to understand the perception of robotics projects) according to the participants' speeches - open coding (1st phase). Subsequently, the codes were grouped according to their properties, forming concepts that represent categories. Finally, these codes were related to each other - axial coding (2nd phase).

The objective of qualitative analysis in this case study was to understand how Educational Robotics, in conjunction with the PBL, can contribute to the development of 21 st Century skills and competencies. Thus, it was decided not to choose the main category because the GT rule is the circularity between collection and analysis stages until the theoretical saturation is reached (Strauss and Corbin, 2014). Therefore, selective coding was not performed (the 3rd phase of the GT method).

Regarding the contribution of the robotics projects, the comments of the students demonstrated that to use Robotics encourages: (I) Creativity (see the quotation from P1), (II) Communication (see the quotation from P2); (III) Teamwork (see the quotation from P3); (IV) Problem-solving (see the quotation from P4), and (V) Resilience (see the quotation from P5).

"I found that the use of Robotics stimulated my creativity. I had to use it at each step of the project" (P1).

"I thought communication with my group was easy. My colleagues were very open to discuss the project" (P2).

“(...) We were very close and worked well together. Each member of the team was able to collaborate with the best they knew how to do" (P3).

"In coding problems, I thought it was cool to think about the solution" (P4).

"We had to be very resilient at work" (P5).

Regarding the contribution of the PBL to the teaching and learning processes, one participant said that the methodology by project makes it possible to encourage $21 \mathrm{st}$ Century competencies and skills (see the quotation from P6). In sequence, one 
participant said that the methodology per project allows interaction between participants (see the quotation from P7). Besides, one participant believes that the project's methodology provides involvement with the activities (see the quotation from P8).

"The Robotics project allowed a great learning experience, as we faced problems and managed to solve them. Next, I managed to learn things I didn't know" (P6)

"During the project, the team walked closely together. Ideas came up, everyone discussed and increased the proposal" (P7).

"Through a project, we were able to learn, help others, and actively participate in the proposal" (P8).

Finally, comments showed that it was possible to encourage 21 st Century skills and competencies. The testimonies indicated that some students, even with difficulties, could deliver their projects through resilience skills. Besides, even without mastery of Robotics, some students managed to finish their work through the use of skills, such as teamwork, communication, and organization.

\section{Discussions}

In general, robotics proved to be a useful technology for students to experience the environment of Education 4.0 through the PBL.

This practice of Education 4.0 could be based on Dewey's pragmatism theory (Dewey, 1979), which argues that students learn better by carrying out practical activities associated with the content learned. Dewey believes that the ideal space for learning is where students can communicate, discuss ideas and, exchange experiences about practical activities (Dewey, 1979).

In this case study, students were free to choose the project type. For Education 4.0, this process is considered dynamic. It allows students to decide what they want to learn, when, how, why, and where. In this way, students have the flexibility to be responsible for building their knowledge (Hartono et al., 2018). At the end of the study, the self-assessment questionnaire became interesting due to allowing the student to exercise his protagonism in its learning process. We believe that students reached a level of maturity during the activities, having the conditions to self-assess.

The results identified in the quantitative analysis showed that most students need to develop autonomy better. We believe that due to the lack of proficiency in this skill, other skills were hindered, for example, "(..) being independent in activities" (learning to learn). Besides, less autonomy may also have affected work management, such as "planning and delegating tasks" (organization). The results identified in the qualitative analysis showed that Robotics linked to PBL encouraged teamwork skill. Therefore, the work methodology allowed students to deal with people in the group, tasks, resources, and schedules to execute different projects. The deficiencies found that refers more to the skills of organization, leadership, and independence should serve as a basis for discussing the pedagogy of the discipline and looking for ways to improve the learning.

In this case study, some benefits from Robotics with PBL are presented. We noticed that these educational approaches could contribute to active learning. The student could work the student's protagonism and learn by doing, besides encouraging 21 st Century skills and competencies, instead of teaching a set of predefined data. 
However, a limitation of this study is related to the size and homogeneity of the sample since there are 20 students from the same university. This number of participants is not ideal from a statistical point of view. Thus, there was a limitation of the results, which are considered the evidence and not conclusive.

\section{Conclusions and Future Works}

This paper presented a case study that aimed to encourage 21 st Century skills and competencies in undergraduate students in Computer Science and graduate students in Informatics. Students provided feedback on Robotics activities with the PBL carried out at the university.

By analyzing the quantitative and qualitative results of this case study, it was possible to notice that the students worked well with teamwork, communication, creativity, and innovation. A student also provided positive feedback on the resilience that is part of socio-emotional skills. This skill allowed students in his group not to give up on the project even in difficulties with robotics. Skills such as organization, leadership, and independence that were less developed in the students will serve as a basis for new directions within the Mobile Robotics class to improve the learning.

With this study, we intend to show the need to train students with 21st Century skills and competencies and disseminate the concept of Education 4.0. Thus, it is believed that education and technology can prepare young to face the challenges, barriers, and work needs of Industry 4.0. Moreover, we intend to work on future activities with organizational skills to train young for Industry 4.0. From that, we believe that it will be possible to improve student learning and cause positive changes in the training of Computer Science students.

\section{Acknowledgment}

This study was developed with the financial support of CNPq (Brazilian National Council for Scientific and Technological Development).

\section{References}

Ayub, E., Wei, G., Luaran, J., Leong, L. (2018). An Exploratory Study of a Framework for Designing and Developing a Massive Online Course as Smart Future Classroom in VLE. Proceedings of the 2nd International Conference on E-Education, EBusiness and E-Technology, pp. 57-62.

Bell, S. (2010). Project-Based Learning for the 21st Century: Skills for the Future", The Clearing House, pp. 39-43, doi: https://doi.org/10.1080/00098650903505415

Causo, A., Vo, G. T., Toh, E., Chen, I. M., Yeo, S. H., Tzuo, P. W. (2015). Developing and benchmarking show \& tell robotic puppet for preschool education. IEEE International Conference on Robotics and Automation, pp. 6114-6119.

CEDEFOP. (2008). Terminology of European education and training policy. A selection of 100 key terms. Luxembourg: Office for Official Publications of the European Communities.

Ciolacu, M., Tehrani, A., Beer, R., Popp, H. (2017). Education 4.0 - Fostering Student Performance with Machine Learning Methods. IEEE 23rd International Symposium for Design and Technology in Electronic Packaging (SIITME), pp. 438-443. doi: 10.1109/SIITME.2017.8259941 
Coskun, S., Gencay, E., Kayikci, Y. (2016). Adapting Engineering Education to Industrie 4.0 Vision. 16th Production Research Symposium, 2016.

Cotet, G., Balgiu, B., Negrea, V. (2017). Assessment procedure for the soft skills requested by Industry 4.0. In MATEC Web of Conferences, v. 121, 2017.

Dewey, J. (1979). Experience and Education". $3^{\text {a }}$ Edition. São Paulo: Cia. National Publisher, 1979.

Eguchi, A. (2018). Educational Robotics for Promoting 21st Century Skills. In Journal of Automation, Mobile Robotics \& Intelligent Systems, 8 (1), pp. 5-11.

English, M. C., Kitsantas, A. (2013). Supporting Student Self-Regulated Learning in Problem- and Project-Based Learning. Interdisciplinary Journal of Problem-Based Learning, 7(2). doi: https://doi.org/10.7771/1541-5015.1339

Hartono, S., Kosala, R., Supangkat, S., Ranti, B. (2018). Smart Hybrid Learning Framework Based on Three-Layer Architecture to Bolster Up Education 4.0. In 2018 International Conference on ICT for Smart Society (ICISS), pp. 1-5.

Intelitek. (2018). The Education 4.0 Revolution: An analysis of Industry 4.0 and its effect on education". (2018). Disponível em: <https://www.intelitek.com/what-iseducation-4-0>. Acesso em: 21 Jan. 2020.

Messias, G., Rodrigues, U., Braga, L., Nakamura, W., Ferreira, B., Paiva, A., Valentim, N. (2018). Education 4.0 and 21st Century Skills: A Case Study with Robotics Activities in Classroom. In: XXIX Brazilian Symposium on Computers in Education, pp. 715-724.

Mourtzis. D. (2018). Development of Skills and Competences in Manufacturing Towards Education 4.0: A Teaching Factory Approach. In J. Ni et al. (Eds.): AMP 2018, LNME, pp. 194-210. doi: 10.1007/978-3-319-89563-5_15

Negrini, L., Giang, C. (2019). How do pupils perceive educational robotics as a tool to improve their 21 st century skills?. Journal of E-Learning and Knowledge Society, 15(2). https://doi.org/10.20368/1971-8829/1628

Oliveira, P., Sommer, L. (2017). Globalization and Digitalization as Challenges for a Professional Career in Manufacturing Industries - Differences in Awareness and Knowledge of Students from Brazil and Germany. Educ. Sci. 2017, v. 7, pp. 55.

Piñol, T. C., Artigas Porta, S., Rodríguez Arévalo, M. C., Minguella-Canela, J. (2017). Study of the training needs of industrial companies in the Barcelona area and proposal of training courses and methodologies to enhance further competitiveness. Procedia Manuf. v. 13, p. 1426-1431, 2017.

Puncreobutr, V. (2016). Education 4.0: New Challenge of Learning”. In St. Theresa Journal of Humanities and Social Sciences, 2016, v. 2 (2), pp. 92-97.

Roessingh, H., Chambers, W. (2011). Project-Based Learning and Pedagogy in Teacher Preparation: Staking Out the Theoretical Mid-Ground. Int. J. Teach. Learn. High. Educ. 2011, 23, pp. 60-71.

Strauss, A., Corbin, J. (2014). Basics of Qualitative Research. Techniques and Procedures for Developing Grounded Theory. Sage Publications, pp. 456.

Winanti, N., Gaol, F., Napitupulu, T., Soeparno, H., Trisetyarso A. (2018). Learning framework in the industrial age 4.0 in higher education. In: 2018 Indonesian Association for Pattern Recognition International Conference (INAPR), pp. 227-232. DOI: $10.1109 /$ INAPR.2018.8627039 